\title{
STUDY OF HEMOGLOBIN LEVELS IN PREGNANT WOMEN AND ITS VARIOUS EFFECTS ON PREGNANCY OUTCOME
}

\author{
Maneesha Shrivastava1, Pradeep Soni², Umesh Sinha ${ }^{3}$, Roshan Chanchlani ${ }^{4}$
}

\section{HOW TO CITE THIS ARTICLE:}

Maneesha Shrivastava, Pradeep Soni, Umesh Sinha, Roshan Chanchlani. "Study of Hemoglobin Levels in Pregnant Women and its Various Effects on Pregnancy Outcome". Journal of Evolution of Medical and Dental Sciences 2014; Vol. 3, Issue 11, March 17; Page: 2740-2745, DOI: 10.14260/jemds/2014/2202

ABSTRACT: INTRODUCTION: When maternal anemia is diagnosed before mid-pregnancy, it has been associated with an increased risk of preterm delivery. High maternal hemoglobin is associated with fetal growth restriction. Several epidemiologic studies have shown that high fetal hemoglobin is associated with lower birth weight and increased incidence of IUGR and intrauterine death. MATERIAL AND METHODS: It was a prospective observational study. All pregnant women attending antenatal clinic with first visit before 18 weeks of gestation were included in the study. Hemoglobin levels were done on women at the first visit to antenatal clinic and also in the third trimester between 34-36 weeks. Outcome criteria were birth weight of neonate, gestational age at delivery, maternal weight gain in pregnancy, development of PIH, IUGR, IUD and preterm labor. RESULTS: Increased weight gain in pregnancy was associated with increase in mean birth weight $r=0.23$ ( $P$ value 0.672 ). Increase in the hemoglobin concentration was associated with increase in birth weight $\mathrm{r}=0.36$ (P value 0.49 ). It was observed that high hemoglobin concentration in pregnancy was associated with more length of gestation but it was not significant $r=0.31$ (P value 0.50 ). CONCLUSION: During early pregnancy normal hemoglobin concentrations were associated with higher birth weights. Weight gain in pregnancy was associated with lower hemoglobin concentrations at term and higher birth weights. The best outcomes of pregnancy were observed in women who had normal hemoglobin concentrations at the onset of pregnancy and who became anemic at term, presumably due to physiologic hemodilution.

KEYWORDS: Anemia, FGI, Gestational age, Hemoglobin levels, IUGR, Pregnancy outcome.

INTRODUCTION: Anemia is the most common Nutritional deficiency disorder in the World. WHO has estimated prevalence of anemia in developed and developing countries in pregnant women is 14 percent in developed and 51 percent in developing countries and 65-75 percent in India. ${ }^{1}$ About one third of global population (over 2 billion) are anemic. ${ }^{2}$ Anemia is the most common indirect cause of maternal mortality in India. Prevalence of anemia among pregnant women in India is $57 \% .{ }^{3}$ Iron deficiency anemia (IDA) is responsible for $95 \%$ of anemia during pregnancy. 4

The World Health Organization (WHO) defined anemia in pregnancy as hemoglobin values $<11 \mathrm{~g} / \mathrm{dl}^{5}$, and Centre for Disease Control (CDC) as a hemoglobin level $<11 \mathrm{~g} / \mathrm{dl}$ during the first and third trimesters and $<10.5 \mathrm{~g} / \mathrm{dl}$ during second trimester. ${ }^{6}$

When maternal anemia is diagnosed before mid-pregnancy, it has been associated with an increased risk of preterm delivery. Maternal anemia detected during the later stages of pregnancy, especially the third trimester, often reflects the expected and necessary expansion of maternal plasma volume. Third trimester anemia usually is not associated with the increase in preterm delivery. ${ }^{7}$ 
Maternal anemia and birth weight: There is a $U$ shape association between maternal hemoglobin concentrations and birth weight. ${ }^{8}$ Abnormally high hemoglobin concentrations usually indicate poor plasma volume expansion and poor plasma perfusion, which is also a risk for low birth weight. High maternal hemoglobin is associated with fetal growth restriction. Several epidemiologic studies have shown that high fetal hemoglobin is associated with lower birth weight and increased incidence of IUGR and intrauterine death. ${ }^{9}$

\section{MATERIALS AND METHODS:}

Study design: A prospective observational study.

Study duration: June 2011 to December 2013.

Study place: Department of Obstetrics and Gynecology, Chirayu medical college and hospital, Bhopal. Sample size and Sampling: 160 women who reported to the antenatal clinic before 18 weeks pregnancy were recruited in the study.

Selection criteria: All pregnant women attending antenatal clinic with first visit before 18 weeks of gestation were included in the study.

Procedure: Hemoglobin levels were done on women at the first visit to antenatal clinic and also in the third trimester between 34-36 weeks by using Sahli's hemoglobinometer. Iron supplementation was continued as per routine policy and a record of time of initiation and duration of therapy was kept.

Outcome criteria were birth weight of neonate, gestational age at delivery, maternal weight gain in pregnancy, development of PIH, IUGR, IUD and preterm labor. The clinical data was gathered in the antenatal clinic pertaining to maternal symptoms, weight gain, fetal growth and amniotic fluid quantity. Fetal growth index (FGR) was derived which is defined as ratio of the observed birth weight to the mean birth weight for that gestational age. They were classified as normal growth if the ratio was between 0.9 - 1.10, mild growth restriction if between $0.8-0.85$, moderate if between $0.75-0.8$ and severe if $<0.75$.

The study was carried out over a period of 18 months. During this period 160 women who reported to the antenatal clinic before 18 weeks pregnancy were recruited in the study and followed until their delivery.

The data collected was entered in the Microsoft office excel 2007. The quantitative variables were summarized using mean and Standard deviation while qualitative variables by percentage and proportions. The spearman correlation was applied to show the correlation between variables. We considered the P-value to be significant when the P-value is less than 0.05 . The data was analyzed using SPSS software.

RESULTS: Out of 160 women studied, 21 had a previous caesarean delivery, 22 women had previous preterm deliveries. Two women had history of postpartum hemorrhage in their previous gestation for which blood transfusion was given. 14 women in their previous pregnancies had given birth to low birth weight infants.

Out of total 160 pregnant women $56(35 \%)$ were primigravida, 58(36.3) were $2^{\text {nd }}$ gravida, $36(22.5 \%)$ were $3^{\text {rd }}$ gravida and $10(6.3 \%)$ were grandmultipara.

Hemoglobin levels done at first visit and between 34-36 weeks are shown in Table no.1. 
Weight of pregnant women was recorded at each antenatal visit, weight gain in the early (before 24 weeks) and the later part of pregnancy was calculated. The maximum weight gain in early pregnancy was $7 \mathrm{~kg}$, mean $3.44 \pm 1.41$ and maximum weight gain in late pregnancy was $13 \mathrm{~kg}$, mean $5.74 \pm 2.1$. Distribution of the pregnant women as per the gestational age at the time of delivery is shown in Table no. 2.

Maximum 110 (68.7\%) of infants delivered had birth weight between $2.5 \mathrm{~kg}$ and $3.5 \mathrm{~kg}$. Severe IUGR (i.e. FGI < 0.75 ) was found in 18(11.25\%) of the fetuses. Of the three stillbirths found in the study, the gestational age at delivery was 30 weeks, 33 weeks and 28 weeks respectively. The birth weights were as 946 grams, 800 grams and 742 grams respectively. The first case was complicated by PIH and prematurity, the second case has severe IUGR with abruption placentae and third case was abruptio placentae.

Increased weight gain in pregnancy was associated with increase in mean birth weight $r=0.23$ (P value 0.672 ) as shown in Table no. 3. There was an association between hemoglobin concentration in early pregnancy and mean birth weight. Increase in the hemoglobin concentration was associated with increase in birth weight $r=0.36$ ( $P$ value 0.49 ) as shown in Table no. 4. It was observed hemoglobin concentration in early or late pregnancy was not associated with IUGR or FGI as shown in Table no. 5. It was observed that high hemoglobin concentration in pregnancy was associated with more length of gestation but it was not significant $r=0.31$ ( $P$ value 0.50 ) as shown in Table no. 6 .

The women who were anemic at the beginning of pregnancy had much more appreciable increase in hemoglobin. The fetal outcomes were best in the group of women who began pregnancy with normal hemoglobin and subsequently became anemic. Presumably these women underwent physiological hemodilution which is also a marker of successful placentation.

DISCUSSION: In present study we observed that increased weight gain in pregnancy was associated with increase in mean birth weight $r=0.23$ (P value 0.672 ). Similar findings were observed in a study done by Ludwig DS and Currie J in 2010.10

In present study we observed that increase in the hemoglobin concentration was associated with increase in birth weight but it was not significant $r=0.36$ (P value 0.49) Same results were found in a study done by K Jagadish Kumar, N Asha1, D Srinivasa Murthy, MS Sujatha2, VG Manjunath in Mysore i.e. mean birth weight was marginally high, but not significant.11

In present study it was observed hemoglobin concentration in early or late pregnancy was not associated with IUGR or FGI. Scholl and Hediger, and Scholl et al studied the relationship between iron deficiency anemia in early and late pregnancy and fetal growth in a cohort of women belonging to a minority in the United States.12,13

Iron deficiency anemia was associated with a greater risk of LBW in early but not late pregnancy. Results from a study in India also suggested a negative effect of anemia during pregnancy on different anthropometric measurements at birth. ${ }^{15}$ Contrary to these results, two studies in different populations (United States and United Kingdom) did not find a relationship between iron status markers (hemoglobin or mean corpuscular volume [MCV]) at different stages of pregnancy and fetal growth outcomes. ${ }^{15,16}$

In present study we observed that high hemoglobin concentration in pregnancy was associated with more length of gestation but it was not significant $r=0.31$ (P value 0.50). Same results were found in a study done by K Jagadish Kumar, N Asha1, D Srinivasa Murthy, MS Sujatha2, VG 
Manjunath in Mysore i.e. mean gestation of the babies born to anemic mothers was lesser compared to babies born to non- anemic mothers. ${ }^{11}$

CONCLUSIONS: During early pregnancy normal hemoglobin concentrations were associated with higher birth weights. Weight gain in pregnancy was associated with lower hemoglobin concentrations at term and higher birth weights. Women compliant to regular iron treatment had higher hemoglobin concentrations, but this did not translate into higher birth weights or gestational ages. The best outcomes of pregnancy were observed in women who had normal hemoglobin concentrations at the onset of pregnancy and who became anemic at term, presumably due to physiologic hemodilution.

\section{REFERENCES:}

1. DeMayer EM, Tegman A. Prevalence of anemia in the World. World Health Organ Qlty 1998; 38:302-16.

2. WHO. Micronutrient deficiency: Battling iron deficiency anaemia: the challenge. Available from:http://www.who.int/nut/ida.htm, accessed on April 24, 2008.

3. Malhotra J. Iron deficiency anemia in India. FOGSI Focus 2009; 9-11.

4. Raja KS, Janjua NB, Khokhar N. Intravenous iron sucrose complex therapy in iron deficiency anemia in the pregnant women. Rawal Med J.2003; 28: 40-3.

5. World Health Organization. Nutritional anemias. Tech Rep Ser 1972; 503.

6. CDC criteria for anemia in children and child bearing aged women. MMWR Morb Mortal Wkly Rep 1989; 38: 400-4.

7. Scanlon KS, Yip R. High and low haemoglobin levels during pregnancy: Differential risks for preterm births and small for gestational age. Obstet Gynecol Nov 2000; 96: 741-8

8. Rasusses K. Is there a causal relationship between iron deficiency anaemia at birth weight, length of gestation and perinatal mortality? J Nutr. Feb 2001;131:590S-601S

9. Lindsay H. Allen. Anaemia and iron deficiency: Effects on pregnancy outcome. Am J Clin Nutr.200; 71.

10. Ludwig DS, Currie J. The association between pregnancy weight gain and birthweight: a withinfamily comparison. Lancet. 2010 Sep 18; 376 (9745):984-90.

11. Kumar J, Asha N, Srinivasa D, Sujatha MS, Manjunath VG. Maternal Anemia in Various Trimesters and its Effect on Newborn Weight and Maturity: An Observational Study. Int J Prev Med.2013; 4:193-9.

12. Scholl TO, Hediger ML. Anemia and iron-deficiency anemia: compilation of data on pregnancy outcome. Am J Clin Nutr. 1994; 59:49.

13. Scholl TO, Hediger ML, Fischer RL, Shearer JW. Anemia vs iron deficiency: increased risk of preterm delivery in a prospective study. Am J Clin Nutr. 1992; 55(5):985-988.

14. Singla PN, Tyagi M, Kumar A, Dash D, Shankar R. Fetal growth in maternal anaemia. J Trop Pediatr. 1997; 43(2):89-92.

15. Scanlon KS, Yip R, Schieve LA, Cogswell ME. High and low hemoglobin levels during pregnancy: differential risks for preterm birth and small for gestational age. Obstet Gynecol. 2000; 96:741748. 
16. Alwan NA, Greenwood DC, Simpson NA, McArdle HJ, Godfrey KM, Cade JE. Dietary iron intake during early pregnancy and birth outcomes in a cohort of British women. Hum Reprod. 2011; 26(4):911-919.

\begin{tabular}{|c|c|c|}
\hline Hemoglobin in gm./dl & First visit n (\%) & 34-36 wks. n (\%) \\
\hline$<7$ & 0 & $8(5)$ \\
\hline $7-9$ & $28(17.5)$ & $38(23.7)$ \\
\hline $9-11$ & $72(45)$ & $72(45)$ \\
\hline $11-13$ & $56(35)$ & $34(21.2)$ \\
\hline$>13$ & $4(2.5)$ & $4(2.5)$ \\
\hline Total & $\mathbf{1 6 0 ( 1 0 0 )}$ & $\mathbf{1 6 0 ( 1 0 0 )}$ \\
\hline
\end{tabular}

Table 1: Distribution of pregnant women according to the Haemoglobin levels done at first visit and between 34-36 weeks

\begin{tabular}{|c|c|c|}
\hline Gestational age at delivery in weeks & Cases & Percentage \\
\hline$<28$ & 2 & 1.25 \\
\hline $28-32$ & 8 & 5 \\
\hline $32-36$ & 14 & 8.75 \\
\hline $36-40$ & 122 & 76.25 \\
\hline$>40$ & 14 & 17.5 \\
\hline Total & $\mathbf{1 6 0}$ & $\mathbf{1 0 0}$ \\
\hline
\end{tabular}

Table 2: Distribution of the pregnant women according to the gestational age at the time of delivery

\begin{tabular}{|c|c|c|c|c|c|}
\hline Total weight gain in $\mathbf{k g}$ & $\begin{array}{c}\text { Cases } \\
\mathrm{N}=156\end{array}$ & $\begin{array}{c}\text { Mean birth } \\
\text { weight }\end{array}$ & $\begin{array}{l}\text { Standard } \\
\text { deviation }\end{array}$ & $\mathbf{r}$ & P value \\
\hline $0-5$ & - & - & - & \multirow{4}{*}{0.23} & \multirow{4}{*}{0.672} \\
\hline $5-10$ & 108 & 2534.3 & 595.8 & & \\
\hline $10-15$ & 46 & 2747.9 & 467.7 & & \\
\hline$>15$ & 02 & 2800.0 & 480.6 & & \\
\hline
\end{tabular}

\begin{tabular}{|c|c|c|c|c|c|c|}
\hline $\begin{array}{l}\text { Hb in } \\
\text { gm./dl }\end{array}$ & $\begin{array}{c}\text { First visit } \\
\mathrm{N}(\%) \\
\end{array}$ & mean $\pm S D$ & $\begin{array}{c}\text { r value } \\
\text { (P value) }\end{array}$ & $\begin{array}{c}\text { 34-36 wks. } \\
\text { N (\%) }\end{array}$ & mean $\pm S D$ & $\begin{array}{c}\text { r value } \\
\text { (P value) }\end{array}$ \\
\hline$<7$ & - & - & \multirow{5}{*}{$0.36(0.49)$} & $8(5)$ & $2783.5 \pm 459$ & \multirow{5}{*}{$\begin{array}{c}0.43 \\
(0.23)\end{array}$} \\
\hline $7-9$ & $28(17.5)$ & $2275.7 \pm 625$ & & $38(23.7)$ & $2399.1 \pm 683$ & \\
\hline $9-11$ & $72(45)$ & $2605.5 \pm 597$ & & $72(45)$ & $2713 \pm 482$ & \\
\hline $11-13$ & $56(35)$ & $2703.0 \pm 492$ & & $34(21.2)$ & $2515.1 \pm 588$ & \\
\hline$>13$ & $4(2.5)$ & $2710.0 \pm 682$ & & $4(2.5)$ & $3010.0 \pm 560$ & \\
\hline Total & $160(100)$ & & & $160(100)$ & & \\
\hline
\end{tabular}


ORIGINAL ARTICLE

\begin{tabular}{|c|c|c|c|c|c|c|}
\hline $\begin{array}{l}\text { Hb in } \\
\text { gm./dl }\end{array}$ & $\begin{array}{c}\text { (Early) Cases } \\
\text { N (\%) }\end{array}$ & $\begin{array}{c}\text { FGI } \\
\text { mean } \pm S D\end{array}$ & $\begin{array}{c}\text { r value } \\
\text { (P value) }\end{array}$ & $\begin{array}{c}\text { (late) Cases } \\
\mathrm{N}(\%)\end{array}$ & $\begin{array}{c}\text { FGI } \\
\text { mean } \pm S D\end{array}$ & $\begin{array}{c}\text { r value } \\
\text { (P value) }\end{array}$ \\
\hline$<7$ & - & - & \multirow{5}{*}{$\begin{array}{c}0.23 \\
(0.45)\end{array}$} & $8(5)$ & $1.07 \pm .16$ & \multirow{5}{*}{$\begin{array}{c}0.17 \\
(0.64)\end{array}$} \\
\hline $7-9$ & $28(17.5)$ & $0.9147 \pm 0.17$ & & $38(23.7)$ & $0.92 \pm .17$ & \\
\hline $9-11$ & $72(45)$ & $0.9987 \pm 0.17$ & & $72(45)$ & $1.04 \pm .13$ & \\
\hline $11-13$ & $56(35)$ & $1.004 \pm 0.15$ & & $34(21.2)$ & $0.94 \pm .21$ & \\
\hline$>13$ & $4(2.5)$ & $0.9490 \pm 0.22$ & & $4(2.5)$ & $1.06 \pm .14$ & \\
\hline Total & $160(100)$ & & & $160(100)$ & & \\
\hline
\end{tabular}

Table 5: Correlation between early and late hemoglobin levels in pregnancy and FGI

\begin{tabular}{|c|c|c|c|c|c|c|}
\hline $\begin{array}{l}\text { Hb in } \\
\text { gm./dl }\end{array}$ & $\begin{array}{c}\text { (Early) } \\
\text { Cases } \\
\text { N (\%) }\end{array}$ & $\begin{array}{c}\text { Gestational age } \\
\text { (in wks.) } \\
\text { mean } \pm \text { SD }\end{array}$ & $\begin{array}{c}\text { r value } \\
\text { (P } \\
\text { value) }\end{array}$ & $\begin{array}{l}\text { (late) } \\
\text { Cases } \\
\text { N (\%) }\end{array}$ & $\begin{array}{c}\text { Gestational age } \\
\text { (in days) } \\
\text { mean } \pm \text { SD }\end{array}$ & $\begin{array}{c}\text { r value } \\
\text { (P } \\
\text { value) }\end{array}$ \\
\hline$<7$ & 0 & 0 & \multirow{5}{*}{$\begin{array}{c}0.31 \\
(0.50)\end{array}$} & $8(5)$ & $264.5 \pm 1.91$ & \multirow{5}{*}{$\begin{array}{c}0.21 \\
(0.46)\end{array}$} \\
\hline $7-9$ & $28(17.5)$ & $36.8 \pm 21.14$ & & $38(23.7)$ & $263.63 \pm 21.57$ & \\
\hline $9-11$ & $72(45)$ & $37.7 \pm 17.01$ & & $72(45)$ & $266.17 \pm 13.29$ & \\
\hline $11-13$ & $56(35)$ & $37.8 \pm 17.46$ & & $34(21.2)$ & $261.59 \pm 17.42$ & \\
\hline$>13$ & $4(2.5)$ & $39.8 \pm 4.24$ & & $4(2.5)$ & $274 \pm 1.41$ & \\
\hline Total & $160(100)$ & & & $160(100)$ & & \\
\hline
\end{tabular}

\section{AUTHORS:}

1. Maneesha Shrivastava

2. Pradeep Soni

3. Umesh Sinha

4. Roshan Chanchlani

\section{PARTICULARS OF CONTRIBUTORS:}

1. Assistant Professor, Department of Obstetrics and Gynaecology, Chirayu Medical College and Hospital, Bhopal.

2. Assistant Professor, Department of Medicine, Chirayu Medical College and Hospital, Bhopal.

3. Associate Professor, Department of Community Medicine, Chirayu Medical College and Hospital, Bhopal.
4. Associate Professor, Department of Surgery, Chirayu Medical College and Hospital, Bhopal.

\section{NAME ADDRESS EMAIL ID OF THE CORRESPONDING AUTHOR:}

Dr. Roshan Chanchlani,

1/6 - Idgah Kothi,

Doctors Enclave, Near Filter Plant,

Idgah Hills, Bhopal - 462001, M. P.

E-mail: roshanchanchlani@gmail.com

Date of Submission: 20/02/2014.

Date of Peer Review: 21/02/2014.

Date of Acceptance: 24/02/2014.

Date of Publishing: 11/03/2014. 